\title{
Comparative Analysis on the Diastolic Blood Pressure of Some Selected Age Groups in Ise-Emure Local Government, Ekiti State
}

\author{
Lasisi T. A. ${ }^{(1)}$, Oladimeji O. A. ${ }^{(2)}$, Ogunbanwo T. S. ${ }^{(3)}$, and Agboluaje S. A. ${ }^{(4)}$ \\ ${ }^{1}$ Department of Mathematics and Statistics, The Polytechnic, Ibadan, Oyo State, Nigeria \\ (taiwolasisi40@yahoo.com) \\ ${ }^{2}$ Department of Statistics, Federal Polytechnic, Ile-Oluji, Ondo State, Nigeria \\ (adedipupo.oladimeji@gmail.com) \\ ${ }^{3}$ Department of Mathematics and Statistics, Osun State College of Technology, Esa-Oke, Osun State, Nigeria \\ (tolualone@gmail.com) \\ ${ }^{4}$ Department of Mathematics and Statistics, The Polytechnic, Ibadan, Oyo State, Nigeria \\ (agbosaheed@yahoo.com)
}

\begin{abstract}
This research work aimed to examine the comparative analysis on the diastolic blood pressure of some selected age group in Ise-Emure Local Government, Ekiti State. The data used for this research work covered the age group between 20 years and above with record of Diastolic blood pressure and patients ages of forty (40) people in Ise-Emure Local Government, Ekiti State. The data used for this research work was secondary which was extracted from the surveyed record of laboratory test department of general hospital, Ise-Emure Local Government, Ekiti State. From the graph, the diagram showed that, as the age increases so also the diastolic blood pressure rises at a slowly manner. The result of the analysis carried out using SPSS from the data revealed that the Pearson's correlation coefficient computed to be $r=0.470$, which implies that there is steady relationship between Age and Diastolic blood pressure of the patients at general hospital Ise-Emure, Ekiti.. From the analysis we observed that the p-value $(0.002)$ is less than the alpha level $(0.05)$, of which we reject $\mathrm{H}_{0}$. Under the test for independence, the $t_{\text {calculated }}$ was computed to be 3.28 while that of corresponding $t_{\text {tabulated }}$ was observed to be 1.686 , of which $t_{\text {calculated }}>t_{\text {tabulated }}$, by comparison $H_{0}$ was rejected.
\end{abstract}

Keywords: Diastolic Blood Pressure, Survey, Hypertension, Pearson Correlation Coefficient, Comparison, Association, Hypothesis, Patients.

DOI: $10.7176 / \mathrm{JHMN} / 95-11$

Publication date: November $30^{\text {th }} 2021$

\section{INTRODUCTION}

Hypertension is defined as systolic and diastolic blood pressures greater than 140 and $90 \mathrm{mmHg}$, respectively (Jennings, 2015). Individuals receiving antihypertensive treatments are also called hypertensive even if they have controlled blood pressure (Lioyd-Jones et al., 2010). The administration of epinephrine in hypertensive patients is associated with an increased risk (Bader, Bonito, and Shugars, 2002), as it can elevate the already raised systolic blood pressure and cause acute hypertensive crisis, hypertensive encephalopathy, brain hemorrhage, and acute left ventricular failure(Lioyd-Jones et al., 2010).

Blood pressure refers to the pressure that blood exerts on the walls of the blood vessels. Systolic blood pressure refers to pressure measured during contraction of the heart and subsequent pumping of blood into the varied vessels, while diastolic pressure refers to blood pressure measures during cardiac relaxation when it gets filled with blood. Blood pressure is measured in units of $\mathrm{mmHg}$ or millimeters of mercury. For adults, the normal blood pressure range is $120 / 80 \mathrm{mmHg}$; it can be somewhat different for men and women over 40 years old. 
Moreover, since chronic hypertension leads to cardiac hypertrophy and atherosclerosis, epinephrineinduced elevations in blood pressure and heart rate may overload the heart and result in angina pectoris, heart attack, and cardiac arrhythmias (Lioyd-Jones et al., 2010). Also, the administration of epinephrine in patients receiving non-selective beta-blockers for the treatment of hypertension can result in hypertensive crisis, since the beta-blocker, block the beta 2 adrenergic receptor and prevents the vasodilatation activity of epinephrine. The use of epinephrine in hypertensive patients using diuretics and calcium channel blockers can also cause hypokalemia and arrhythmia (Lioyd-Jones et al., 2010).

Adults and Children Blood Pressure Chart Per Age

\begin{tabular}{|l|c|c|}
\hline \multicolumn{1}{|c|}{ BP Level } & Diastolic pressure in $\mathbf{m m H g}$ & Systolic pressure in mmHg \\
\hline Hypotension/Low BP & 35 to 60 & 50 to 90 \\
\hline Mild low BP & 60 to 70 & 90 to 100 \\
\hline Normal BP & 70 to 85 & 100 to 130 \\
\hline Mild high BP & 85 to 90 & 130 to 140 \\
\hline Moderately high BP & 90 to 110 & 140 to 160 \\
\hline Hypertension/High BP & 110 to 135 & 160 to 230 \\
\hline
\end{tabular}

\section{AIM AND OBJECTIVES OF THE STUDY}

This research work aimed to examine the comparative analysis on the diastolic blood pressure of some selected age group in Ise-Emure Local Government, Ekiti State.

The objectives the study are to:

1. Examine the pattern of diastolic blood pressure of some selected age group graphically.

2. Examine the degree of association between diastolic blood pressure and age group using Pearson's correlation coefficient.

3. Test for the existence of association between diastolic blood pressure and the selected ages.

\section{SOURCE OF DATA}

The data used for this paper was secondary which was extracted from the surveyed record of laboratory test department of general hospital, Ise-Emure Local Government, Ekiti State.

\section{LITERATURE REVIEW}

A central fat distribution is a better predictor for hypertension than overall fat mass. Early studied show a good correlation between the waist-to-hip ratios (Lapidus et al, 2008. Laisson et al, 2004) and blood pressures levels. Later studied using computed tomography to measure the exact amount of visceral adipose tissue (Peiris et al. 2009. Kanal et al, 2009) showed strong correlation with systolic and diastolic blood pressure level. Recently waist circumference has been proposed as an indicator of abdominal fat mass and a waist circumference. Above $88 \mathrm{~cm}$ in women and above $102 \mathrm{~cm}$ in men. Has been shown to correlation with blood pressure level both in European (Han et al. 2005) and African population.

Lawlor et al (2007) provide evidence for an inverse association of gestation age with systolic blood pressure at age 17-19 year in both siblings and no sibling. Gestation length has also been linked to raise blood pressure in children. Blood pressure in adulthood is unequivocally positively associated with disease and stroke risk and recent research has suggested that increased pulse pressure defined as the difference between systolic and diastolic blood pressure may also be an important component of increased risk of cardiovascular disease, particularly when observed in conjunction with raised systolic blood pressure (Franklin et al, 2007).

Prospective studied have shown that obesity increase the risk of developing hypertension (Friedman et al. 2008, Youg et al, 2008). Weight gain in adult life especially seems to be an important risk factor for the 
development of hypertension (Friedman et al. 2008, Huag et al, 2008). In a recent updated evaluation of the nurses' health study (Huag et al, 2008). A long term follow up study of more than 80,000 female nurses. BMI at 18 years of age and midlife were positively associated with the occurrence of hypertension long term and medium term weight loss was associated with a reduced risk in the group of women with a high base line BMI.

In a recent study by Kanai et al.(2009). The change in mean blood pressure after weight reduction was correlation with change in visceral fat area and not with change in body weight of BMI. This suggest that a decrease in intra-abdominal fat reduces blood pressure in obese hypertension patient. A reduced in body weight can be achieved by a decrease in energy intake and/or an increase in energy expenditure comprehensive weight loss programs include a dietary a behavioral and a physical activity component. Rocchini et al (2008) showed in a group of 72 obese adolescent that a combination of caloric restriction, behavior change alone.

In contrast a recent study by Dengel et al, (2008). In which the independent and combined effect of weight loss and acrobic exercise on blood pressure were studied in a group of older men. Combining the two interventions did not reduce blood pressure to a greater degree than the two interventions did independently. An age dependent factor might explain this difference in outcome.

Geller et al. (2009) conducted a study on 227 males of age at least 40 years. Who are with invasive melanoma?

Ito.et al (2007).In their attempt to determine the level of Crythrocyte aidose reductase protein (AR-p) in diabetic patient by a two-site enzyme linked immunosorbent assay. Classified 95 non-insulin-dependent diabetes mellitus (NIDDOM) patient into two groups. Based on the result of seven nerve function tests: group I, without demonstrable neuropathy and group II, with overt neuropathy. Multivariate logistic regression analysis was subsequently used to identify two independent risk factor for overt neuropathy in diabetic patients. Takahashi et al. (2008). Dauziel et al (2007) recently reported that adults born moderately preterm had increase blood pressures at 30 year of age. Low gestation at birth was the key feature of this association. Whereas birth weight adjusted for gestation age was not. Other studied support this observation.

\section{METHODOLOGY}

\section{STATISTICAL TOOL USED}

\section{Product Moment Correlation Coefficient}

The sample correlation coefficient (r) will be used for this research work which is given by

$$
r_{x y}=\frac{n \sum x y-\sum x \sum y}{\sqrt{\left[\left(n \sum x^{2}-\left(\sum x\right)^{2}\right)\left(n \sum y^{2}-\left(\sum y\right)^{2}\right)\right]}}
$$

\section{Test For Independence of Association}

The test of Hypothesis for comparison of the association between Age and diastolic blood pressure is given as:-

$H_{0}: r=0$ (There is no association between age and diastolic blood pressure)

$H_{1}: r \neq 0$ (There is association between age and diastolic blood pressure)

The corresponding test statistics is given as:

$$
t=r \frac{\sqrt{n-2}}{\sqrt{1-r^{2}}}
$$




\section{ANLYSIS OF DATA}

The data on Diastolic blood pressure recorded at Ise-Emure General Hospital, Ekiti State

\begin{tabular}{|c|c|c|}
\hline Patients selected & Age (years) & Diastolic BP (mmHg) \\
\hline 1 & 57 & 80 \\
\hline 2 & 35 & 67 \\
\hline 3 & 49 & 99 \\
\hline 4 & 67 & 87 \\
\hline 5 & 53 & 84 \\
\hline 6 & 27 & 72 \\
\hline 7 & 36 & 56 \\
\hline 8 & 64 & 87 \\
\hline 9 & 48 & 76 \\
\hline 10 & 36 & 76 \\
\hline 11 & 66 & 67 \\
\hline 12 & 34 & 85 \\
\hline 13 & 72 & 83 \\
\hline 14 & 40 & 83 \\
\hline 15 & 28 & 52 \\
\hline 16 & 31 & 83 \\
\hline 17 & 45 & 83 \\
\hline 18 & 25 & 52 \\
\hline 19 & 65 & 100 \\
\hline 20 & 45 & 89 \\
\hline 21 & 38 & 72 \\
\hline 22 & 23 & 73 \\
\hline 23 & 60 & 61 \\
\hline 24 & 35 & 78 \\
\hline 25 & 20 & 69 \\
\hline 26 & 27 & 85 \\
\hline 27 & 73 & 90 \\
\hline 28 & 50 & 85 \\
\hline 29 & 81 & 89 \\
\hline 30 & 65 & 67 \\
\hline 31 & 74 & 90 \\
\hline 32 & 38 & 76 \\
\hline 33 & 35 & 56 \\
\hline 34 & 24 & 79 \\
\hline 35 & 22 & 72 \\
\hline 36 & 45 & 77 \\
\hline 37 & 25 & 77 \\
\hline 38 & 63 & 110 \\
\hline 39 & 50 & 80 \\
\hline 40 & 36 & 79 \\
\hline
\end{tabular}

Source: Ise-Emure General Hospital, Ekiti State (survey 2020) 


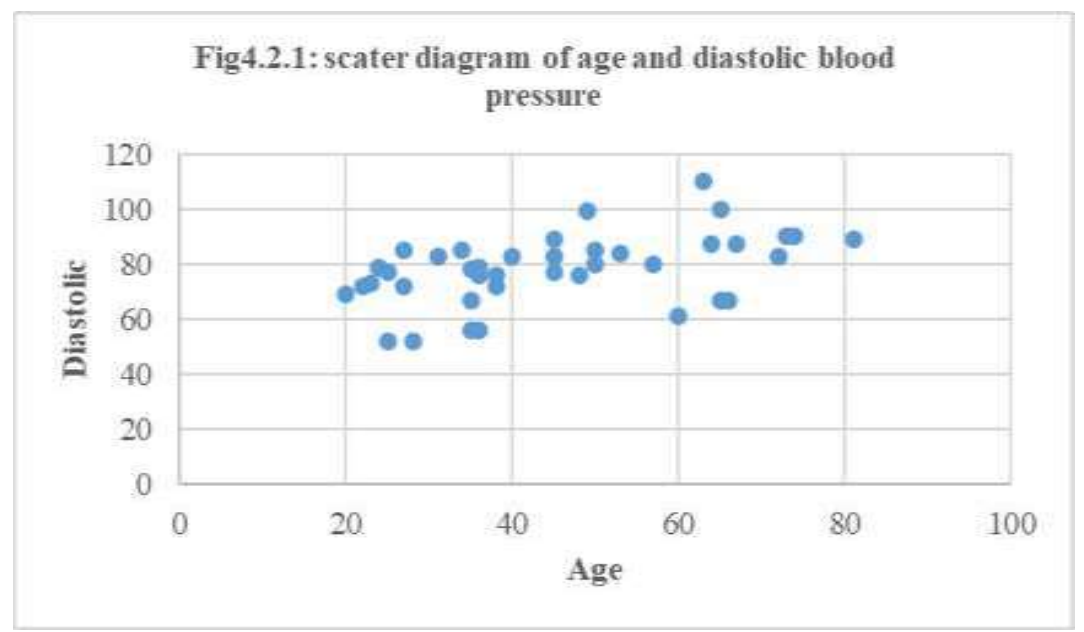

The Graph above showed that, as the age increases so also the diastolic blood pressure rises

Descriptive Statistics

\begin{tabular}{|l|l|l|l|}
\hline & Mean & Std. Deviation & N \\
\hline age of patients (years) & 45.1750 & 17.07132 & 40 \\
Diastolic BP (mmHg) & 78.1500 & 12.54029 & 40 \\
\hline
\end{tabular}

\section{Correlations}

\begin{tabular}{|ll|l|l|}
\hline & & Age of patients (years) & Diastolic BP (mmHg) \\
\hline & Pearson & 1 & $.470^{* *}$ \\
age of patients (years) & Correlation & & .002 \\
& Sig. (2-tailed) & & 40 \\
& $\mathrm{~N}$ & 40 & 1 \\
& Pearson & $.470^{* *}$ & \\
& Correlation & .002 & 40 \\
Diastolic BP (mmHg) & Sig. (2-tailed) & $\mathrm{N}$ & \\
& & \\
\end{tabular}

**. Correlation is significant at the 0.01 level (2-tailed).

\section{Hypothesis:}

$\mathrm{H}_{\mathrm{o}}$ : Age and Diastolic blood pressure $(\mathrm{mmHg})$ of patients are independent.

$\mathrm{H}_{1}$ : Age and Diastolic blood pressure $(\mathrm{mmHg})$ of patients are dependent.

The p-value $=0.002$, alpha level $=0.05$.

Decision rule: Since the p-value is less than the alpha level used, we reject $\mathrm{H}_{\mathrm{o}}$

Conclusion: Since the p-value (0.002) is less than the alpha level (0.05), we reject $\mathrm{H}_{\mathrm{o}}$ and conclude that the Age of the patients depends on their Diastolic blood pressure.

The correlation coefficient $r=0.470$ indicates a positive correlation which means increase in age of patients is increase in the diastolic blood pressure $(\mathrm{mmHg})$ in such patients.

Test for independence $(\rho=0)$

$\mathrm{H}_{\mathrm{o}}:(\rho=0)$ Age and Diastolic blood pressure $(\mathrm{mmHg})$ of patients are independent.

$\mathrm{H}_{1}:(\rho \neq 0)$ Age and Diastolic blood pressure $(\mathrm{mmHg})$ of patients are dependent.

Alpha level $=0.05, \quad$ t-tabulated $=1.686$ 
Test statistic: $t=r \frac{\sqrt{n-2}}{\sqrt{1-r^{2}}}$

Decision rule: Reject Ho if $\mathrm{t}$-calculated is greater than $\mathrm{t}$-tabulated.

$$
t=0.47 \frac{\sqrt{40-2}}{\sqrt{1-0.47^{2}}}
$$

$$
\mathrm{t}=3.28 \text {. }
$$

Decision: Since t-cal $=3.28$ is greater than $\mathrm{t}-\mathrm{tab}=1.686$, we reject Ho.

Conclusion: Age and Diastolic blood pressure $(\mathrm{mmHg})$ of patients are dependent.

\section{SUMMARY OF FINDINGS}

From the previous chapter, the graph plotted showed that, as the age increases so also the diastolic blood pressure rises at a slowly manner. The result of the analysis carried out using SPSS from the data revealed that the Pearson's correlation coefficient computed to be $r=0.470$, which implies that there is steady relationship between Age and Diastolic blood pressure of the patients at general hospital Ise-Emure, Ekiti..

From the analysis we observed that the p-value (0.002) is less than the alpha level $(0.05)$, of which we reject $\mathrm{H}_{\mathrm{o}}$ and conclude that the Age of the patients depends on their Diastolic blood pressure. Under the test for independence, the $t_{\text {calculated }}$ was computed to be 3.28 while that of corresponding $t_{\text {tabulated }}$ was observed to be 1.686, of which $t_{\text {calculated }}>t_{\text {tabulated }}$, by comparison $H_{0}$ was rejected, this implies that, Age and Diastolic blood pressure $(\mathrm{mmHg})$ of patients are dependent.

\section{CONCLUSSION}

From the findings of the analysis stated above, I can conclude that the age and diastolic blood pressure are dependent, that is, existence of diastolic blood pressure in a person depends on the age that person attained. Hence, this might be as a result of some health factors associated with human development but cannot be discussed in this study.

\section{REFERENCES}

Bader, J. D., Bonito, A. J., \& Shugars, D. A. (2002). A systematic review of cardiovascular effects of epinephrine on hypertensive dental patients. Oral Surg Oral Med Oral Pathol Oral Radiol Endod, 93(6), 647653. http://dx.doi.org/10.1067/moe.2002.123866

Dalziel SR,Parag V, Rodegers A, Harding JE. (2007): Cardovascular risk factors at age 30 following preterm birth. Int J Epidemiol; 36: 907-915.

Dengel DR, Galecki AT, Hagberg JM, Pratley RE. (2008): The independent and combined effects of weight loss and aerobic exercise on blood pressure and oral glucose tolerance in older men. Am J Hypertens.; $11: 1405-12,7$.

Friedman GD, Selby JV, Quesenberry CP, Armstrong MA. Klatsky AL, (2008): Precursors of essential hypertension. Prev Med.; 17:387-402.

Franklin, E.D (2007): Clinical management of the obese hypertensive patient. Cardiol Rev. $10 \quad$ (3): 127-138.

Geller AC, Johnson MD. Miller DR. Brooks, K.R. Layton C.J. Susan, M. et al (2009). Factor associated with physical discovery carly melanoma in middle-aged and older men. Arch Dermatol, 145(4), 409-414.

Han K, Whitsel EA (2013): Discordance in national estimates of hypertension among young adults. Epidemiology. 22(4):532-541. 
Huag Z, Willett WC and manson J.E (2008): Body weight, weight change and risk for hypertension women. Ann intern Med: 128:81-8.

Ito MJ, Grobbee DE, peeter PH, Bots Mt. (2017): Average blood pressure and cardiovascular related mortality in middle aged women. Am .1 Hypertens; 18: 197-201.

Jennings, G. L. (2015). A New Guideline on Treatment of Hypertension in Those with Coronary Artery Disease: Scientific Statement from the American Heart Association, American College of Cardiology, and American Society of Hypertension about Treatment of Hypertension in Patients with Coronary Artery Disease. Heart, Lung and Circ, 24(11), 1037-40. http://dx.doi.org/10.1016/j.hlc.2015.05.022

Kanai H. Tokunaga K. (2009): Decrease in intra-abdominal visceral fat may reduce blood pressure obese hypertensive women. 27:125-9.

Lapidus L. Bengtsson C. (2008): Distribution of adipose tissue and risk of cardiovascular death: a 12 year follow up of participants in the population study of women in Gothenburg Sweden. $\quad \operatorname{Br}$ med j., 289:125761.

Larsson B. Sva" Rdudd k. (2014): Abdominal adipose tissue and risk of cardiovascular disease and death: 13 year follow up of participants in the study of men born in 1913. Br Med J $\quad 2004 ; 288: 1401-4$.

Lawlor DA, Hubinette A. (2007): Associations of gestation age and intrauterine growth with systolic blood pressure in a family based study of 386,485 men in 331,089 families. 115: $\quad$ 562-568.

Lioyd-Jones, D., Adams, R. J., Brown, T. M., Carnethon, M., Dai, S. F., De Simone, G., \& Wylie- Rosett, J. (2010). Executive summary. Heart disease and stroke statistics update: A report from the American Heart Association. Circulation, 121(7), e46-e215. http://dx.doi.org/10.1161/CIRCULATIONAHA.109.192667

Peiris AN, Sothmann MS. (2009): Fat distribution and cardiovascular risk. Ann interm Med. 110:867-72

Rocchini AP. Katch V. Anderson J,et al. (2008):blood pressure in obese adolescents, effect of weight loss pediatrics:82:16-23.

Takahashi Y, (2008). Erythrocyte aldose reductase protein a clue to elucidate risk factor for diabetic neuropathics independent of glycemic control. Diabetic research and clinical practice 42(2), 101-107.

Youg S.S, Nwankwo T, Wright JD, Hong Y, Burt V (2015). Trends in blood pressure among adults with hypertension: United States, 2003 to 2012. Hypertension. 65:54-61. 